\title{
Measurement station for interim inspections of Lightbridge metallic fuel rods at the Halden Boiling Water Reactor
}

\author{
C. Hartmann, A. Totemeier, S. Holcombe, J. Liverud, M. Limi, J.E. Hansen, E. Navestad
}

\begin{abstract}
Lightbridge Corporation has developed a new Uranium-Zirconium based metallic fuel. The fuel rods are manufactured via a co-extrusion process, and are characterized by their multi-lobed (cruciform-shaped) cross section. The fuel rods are also helically-twisted in the axial direction. Two experimental fuel assemblies, each containing four Lightbridge fuel rods, are scheduled to be irradiated in the Halden Boiling Water Reactor (HBWR) starting in 2018. In addition to on-line monitoring of fuel rod elongation and critical assembly conditions (e.g. power, flow rates, coolant temperatures, etc.) during the irradiation, several key parameters of the fuel will be measured out-of-core during interim inspections. An inspection measurement station for use in the irradiated fuel handling compartment at the HBWR has therefore been developed for this purpose. The multi-lobed cladding cross section combined with the spiral shape of the Lightbridge metallic fuel rods requires a high-precision guiding system to ensure good position repeatability combined with low-friction guiding. The measurement station is equipped with a combination of instruments and equipment supplied from third-party vendors and instruments and equipment developed at Institute for Energy Technology (IFE). Two sets of floating linear voltage differential transformer (LVDT) pairs are used to measure swelling and diameter changes between the lobes and the valleys over the length of the fuel rods. Eddy current probes are used to measure the thickness of oxide layers in the valleys and on the lobe tips and also to detect possible surface cracks/pores. The measurement station also accommodates gamma scans. Additionally, an eddy-current probe has been developed at IFE specifically to detect potential gaps or discontinuities in the bonding layer between the metallic fuel and the Zirconium alloy cladding. Potential gaps in the bonding layer will be hidden behind a $0.5-1.0 \mathrm{~mm}$ thick cladding wall. It has therefore been necessary to perform a careful design study of the probe geometry. For this, finite element analysis (FEA) has been performed in combination with practical validation tests on representative fuel dummies with machined flaws to find the probe geometry that best detects a hidden flaw. Tests performed thus far show that gaps down to $25 \mu \mathrm{m}$ thickness can be detected with good repeatability and good discrimination from lift-off signals.
\end{abstract}

The work presented here was performed at IFE's facilities in Halden in collaboration with Lightbridge Corporation. It is part of the irradiation test program developed by Lightbridge to demonstrate the performance of the $\mathrm{Zr}$ $\mathrm{U}$ metallic fuel. The fuel irradiation and interim inspections will be performed in an isolated loop of the Halden Boiling Water Reactor.

C. Hartmann, S. Holcombe, J. Liverud, M. Limi, J.E. Hansen and E. Navestad are with Institute for Energy Technology, P.O. Box 173, NO1751 Halden, Norway (e-mail: christian.hartmann@ife.no).

A. Totemeier is with Lightbridge Corporation, 11710 Plaza America Dr., Ste. 2000, Reston, VA 20190 USA (e-mail: atotemeier@1tbridge.com).
Index Terms-Lightbridge, metallic fuel, NDT, interim inspection, eddy-current probe

\section{INTRODUCTION}

$\mathrm{L}$ IGHTBRIDGE Corporation is a U.S. company that has $J_{\text {developed a design and fabrication process for a novel }}$ nuclear fuel [1], consisting of helically twisted metallic Uranium-Zirconium alloy fuel rods. Lightbridge's fuel technology can improve plant safety, significantly enhance the nuclear power industry's economics and increase power output of existing and new light water nuclear reactors. In order to verify the performance of the Lightbridge fuel and acquire experimental data to support implementation of this fuel type into commercial nuclear power reactors, test irradiations of Lightbridge metallic fuel rods will be carried out in the Halden Boiling Water Reactor (HBWR), a research reactor located in Halden, Norway.

In addition to monitoring characteristic fuel performance parameters in real time during the test irradiation [2], interim inspections of the test fuel rods will be performed between operating cycles. Since the metallic, helically twisted Lightbridge fuel rods differ from the standard cylindrical Uranium Oxide fuel, new inspection equipment was needed in order to perform the interim inspections. For several inspection techniques it was sufficient to design a system with fixtures capable of holding the helically twisted fuel rods; however, some inspections required development of new measurement instrumentation. This paper describes some key features of the new interim inspection equipment and development of new instrumentation.

\section{LIGHTBRIDGE FUEL}

The fuel rods are manufactured through a co-extrusion process, and are characterized by their cruciform-shaped cross section. The fuel rods are also helically twisted in the axial direction. A rendering of the Lightbridge fuel rod design is shown in Fig. 1 with cross-sections showing the main dimensions and the definitions of the lobe and valley of the fuel rod. 


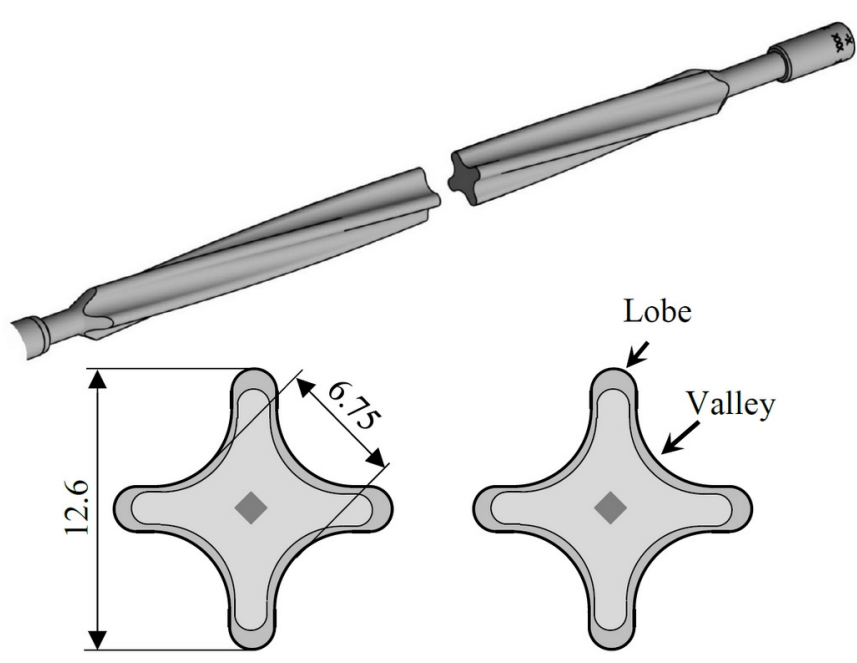

Fig. 1. Lightbridge metallic fuel rod with cross sections showing the characteristic, cruciform design. The Zirconium-alloy cladding is metallically bonded to the Uranium-Zirconium fuel core. The central displacer (diamond in the center) consists of Zirconium or a Zirconium alloy containing burnable neutron absorbers.

Lightbridge fuel rods differ from conventional fuel currently used in commercial nuclear power reactors. Conventional fuel rods consist of cylindrical Zirconium-alloy tubes filled with cylindrical ceramic Uranium Dioxide fuel pellets, where there is a gas-filled gap between the fuel pellet outer surface and the inner surface of the Zirconium-alloy cladding tubes. The Lightbridge fuel is cruciform-shaped instead of cylindrical, metallic instead of ceramic, and the cladding is metallically bonded to the fuel instead of incorporating the presence of a gas-filled gap. These features mean that thermal performance of the Lightbridge fuel is superior to conventional fuel rods, and enable operating the fuel at higher power density while at the same time increasing safety margins.

\section{INSPECTION MEASUREMENT STATION}

A conceptual model of the interim inspection equipment is shown from different angles in Fig. 2. The interim inspection equipment is designed to be placed into a fuel handling compartment. The upper end of the Lightbridge fuel rod is held in a chuck fixed to the rotational motor. The lower end of the Lightbridge fuel rod passes through the measurement station. The rotational motor fixture is moved vertically such that the Lightbridge fuel rod moves through the measurement station. The rotational motor is used to read out the rotational position of the rod, and can be used to rotate the rod into position for alignment with the guide wheels in the measurement station.

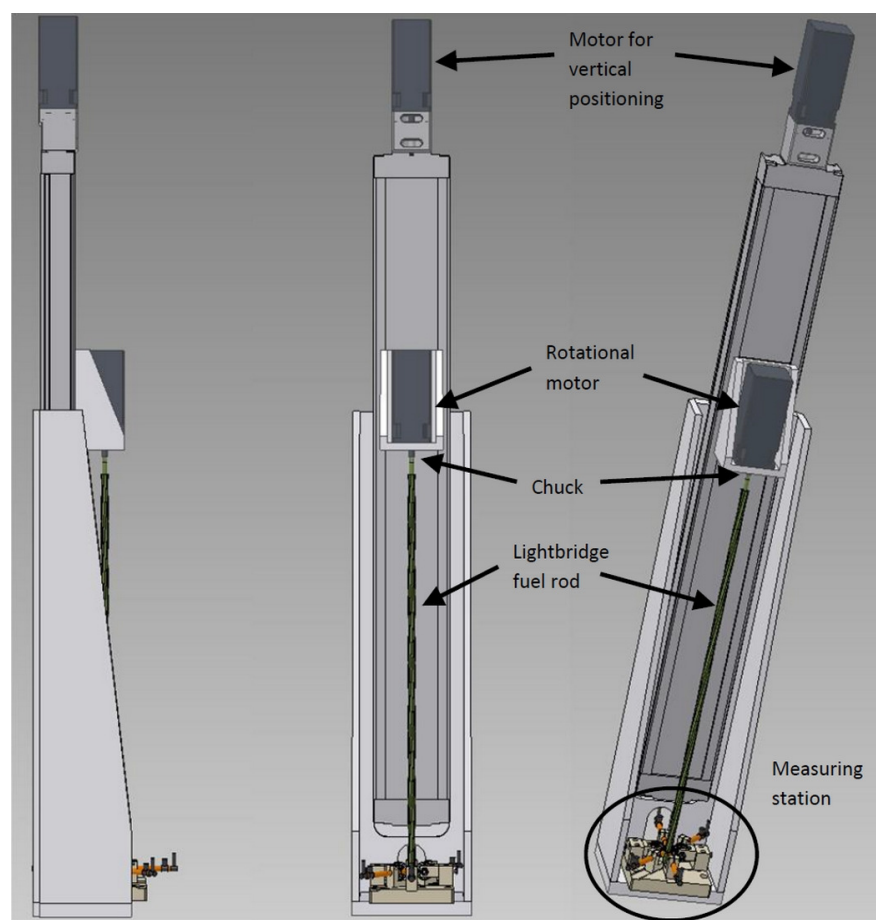

Fig. 2. Lightbridge measurement station. The encircled area in the lower right corner is shown in detail in Fig. 3.

A conceptual model of the measurement station is shown in Fig. 3. Two spring-loaded guide wheels, placed $180^{\circ}$ apart, guide the Lightbridge fuel rod through the measurement station and maintain the position of the rod relative to the measurement probes. Different kinds of probes can be fixed into the measurement station where the probes are placed in order to perform measurements on the fuel rod lobe tips and in the valleys between the lobes. The types of probes which may be installed include eddy-current probes for measuring oxide thickness, LVDTs for measuring diameter and swelling, and an eddy-current probe for investigating fuel-clad metallurgical bond integrity.

\section{FUEL GROWTH}

Lightbridge metallic fuel rods are expected to swell in the radial direction, where swelling is expected to preferentially occur in the valleys between the lobes.

\section{A. Measurement principle}

Radial fuel growth is planned to be investigated by measuring the distance between opposing valleys and by measuring the circumscribed diameter (i.e. the distance between opposing lobe tips) using opposing mechanical probes, each coupled to LVDTs. The LVDTs will be placed into the measurement head as shown in Fig. 3. 


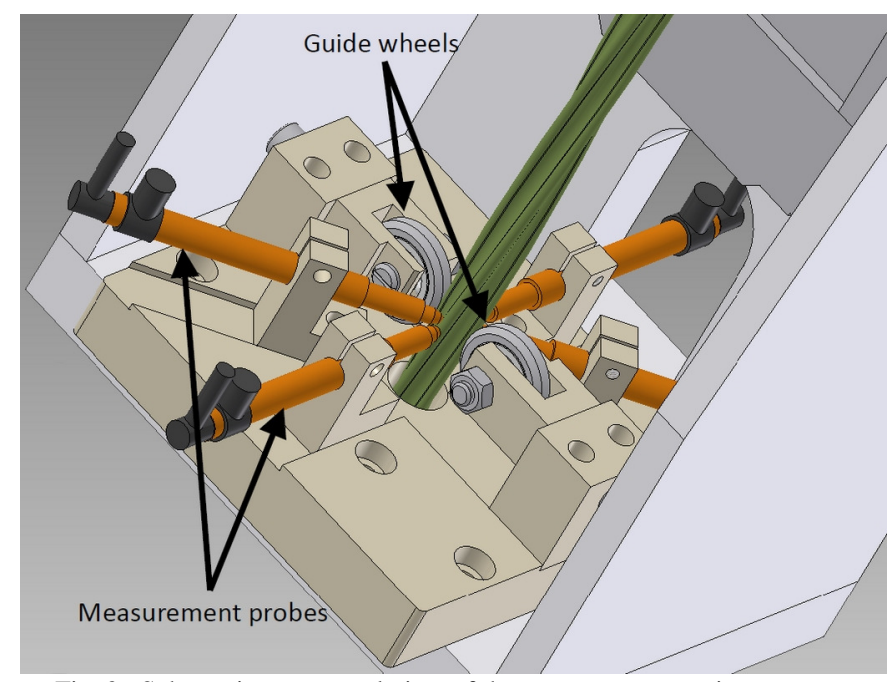

Fig. 3. Schematic conceptual view of the measurement station.

\section{B. Mock-up tests}

Testing of the fuel growth measurement precision was performed using a setup similar to that shown in Fig. 4.

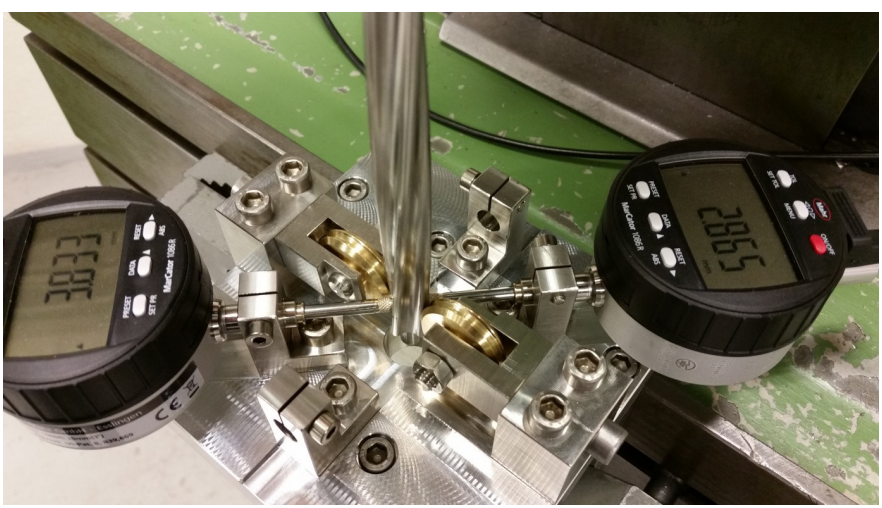
design.

Fig. 4. Photo of a mock-up of the measurement station used for testing the

The distance between opposing probes was measured on a dummy Lightbridge fuel rod at 6 axial locations between the valleys and at 6 axial locations between the lobe tips. The measurements were repeated 10 times, where each axial location was measured once before moving to the next axial location. The standard deviations of the measured thicknesses were calculated for the set of 10 measurements acquired for each of the 6 axial positions. The maximum and minimum standard deviations are shown in Table I along with the maximum and minimum absolute magnitudes of the deviations within each set of measurements.
TABLE I

STANDARD DEVIATIONS AND ABSOLUTE DEVIATIONS

Standard deviation of the set of Absolute deviation of the measurements performed at set of measurements each axial position of the performed at each axial

\begin{tabular}{cccc}
\multicolumn{2}{c}{ dummy rod } & \multicolumn{2}{c}{ position of the dummy rod } \\
\hline Maximum & Minimum & Maximum & Minimum \\
from all & from all & from all & from all
\end{tabular}

positions $\quad$ positions $\quad$ positions $\quad \begin{array}{cc}\text { prom all } \\ \text { positions }\end{array}$

\begin{tabular}{lcccc} 
& positions & positions & positions & positions \\
\hline $\begin{array}{l}\text { Lobe } \\
\text { tips }\end{array}$ & $0.6 \mu \mathrm{m}(1 \sigma)$ & $0.3 \mu \mathrm{m}(1 \sigma)$ & $\pm 1.0 \mu \mathrm{m}$ & $\pm 0.5 \mu \mathrm{m}$ \\
$\begin{array}{l}\text { Valleys } \\
0.8 \mu \mathrm{m}(1 \sigma)\end{array}$ & $0.4 \mu \mathrm{m}(1 \sigma)$ & $\pm 1.0 \mu \mathrm{m}$ & $\pm 0.5 \mu \mathrm{m}$ \\
\hline
\end{tabular}

\section{OXIDE THICKNESS}

The oxide thickness on the fuel cladding will be measured at each interim inspection, using IFE's eddy-current system, based on an Elotest N300 instrument and eddy-current probes from GE.

\section{A. Measurement principle}

A picture of the oxide thickness measurement probe mounted in the measurement head is shown in Fig. 5.

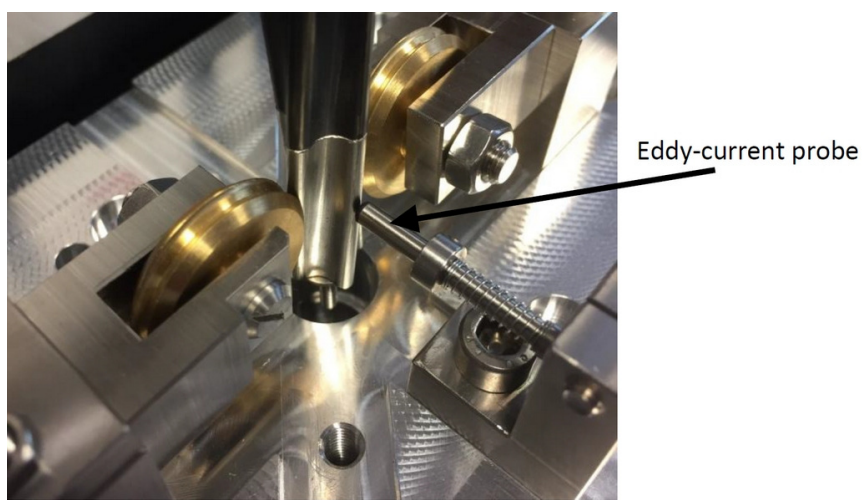

Fig. 5. Eddy-current probe for oxide thickness measurements mounted in mock-up test station together with a fuel rod dummy.

Prior to the execution of the oxide thickness measurements, the probe and electronics will be calibrated on an un-oxidized reference sample utilizing calibration foils of known thickness.

\section{B. Mock-up tests}

A dummy rod for testing of oxide thickness measurements was manufactured by IFE. It consisted of four segments, which were assembled into a single dummy rod. Two of the segments, assembled on the upper and lower ends of the dummy rod, were un-oxidized and two segments assembled in the middle of the dummy rod, each had different oxide thicknesses. The assembled dummy rod is shown in Fig. 6. 


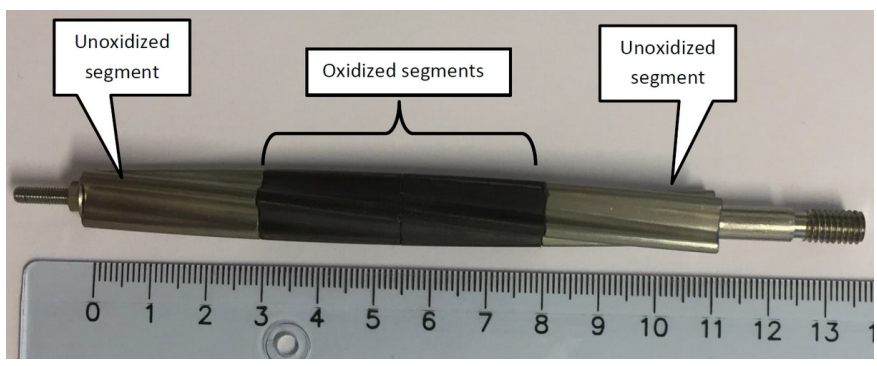

Fig. 6. Photo of the dummy rod used for testing oxide thickness measurements in the mock-up of the measurement station.

The two oxidized segments were oxidized in steam and the resulting oxide thickness was assessed using Light Optical Microscopy (LOM) on a $5 \mathrm{~mm}$ long segment cut from the end of each oxidized segment. The oxidation parameters and the resulting oxide thicknesses are shown in Table II.

TABLE II

OXIDATION PARAMETERS AND RESULTING OXIDE THICKNESS

\begin{tabular}{|c|c|c|c|}
\hline & \multicolumn{2}{|c|}{ " Oxidation parameters } & \multirow{2}{*}{$\begin{array}{l}\text { Oxide thickness } \\
\qquad(\mu \mathrm{m})\end{array}$} \\
\hline & $\begin{array}{c}\text { Time } \\
\text { (minutes) }\end{array}$ & Temperature $\left({ }^{\circ} \mathrm{C}\right)$ & \\
\hline Sample 1 & 30 & 750 & 5.5 \\
\hline Sample 2 & 30 & 900 & 13.0 \\
\hline
\end{tabular}

Oxide thickness eddy-current measurements were performed on the lobe and in the valley of the dummy test rod. The results from these tests are summarized in Table III.

TABLE III

SUMMARY OF OXIDE THICKNESS MEASUREMENTS

\begin{tabular}{lcccc}
\hline \hline & \multicolumn{2}{c}{$13 \mu \mathrm{m}$ oxide } & \multicolumn{2}{c}{$5.5 \mu \mathrm{m}$ oxide } \\
& \multicolumn{2}{c}{ thickness segment } & \multicolumn{2}{c}{ thickness segment } \\
& Lobe & Valley & Lobe & Valley \\
\hline Minimum $(\mu \mathrm{m})$ & 10.0 & 14.6 & 3.0 & 3.7 \\
Maximum $(\mu \mathrm{m})$ & 13.0 & 16.6 & 4.6 & 5.3 \\
Radial variation $(\mu \mathrm{m})$ & $< \pm 0.8$ & $< \pm 0.6$ & $< \pm 0.5$ & $< \pm 0.5$ \\
\hline \hline
\end{tabular}

\section{SURFACE CRACKS}

It is planned to use a third-party eddy-current probe for detection of surface cracks. The development and qualification of a surface crack-detection system is pending.

\section{GAMMA SCANNING}

Gamma rays are emitted by radioactive nuclides present in irradiated fuel and the content and distribution of these nuclides corresponds to operating conditions of the fuel. Measuring the distribution of the gamma-ray activity can therefore be used to assess various fuel performance characteristics, such as power and/or burnup distribution, or migration of volatile nuclides within the fuel.

Lightbridge fuel rods will be characterized by measuring the axial distribution of selected gamma-rays. The fuel rods will be placed into the interim inspection equipment in a fuel handling compartment, a collimated High Purity Germanium (HPGe) detector is inserted through an opening in the compartment wall, and the fuel rod will be moved axially past the collimator opening. The guide-wheel fixture in the interim inspection equipment will hold the fuel rod lobes as the fuel is moved axially, thereby rotating the fuel rod with the helical twist such that the fuel geometry relative to the detector will be the same for all axial positions, i.e. the axial gamma scanning will follow the twist of the fuel rods. In this way, radial as well as axial information will be acquired.

\section{FUEL-CLADDING DE-BONDING}

When manufactured, a bond is formed between the fuel and cladding during the co-extrusion process. This bond provides good thermal conductivity between fuel and cladding. The bond is expected to be maintained during irradiation, but if any gaps between cladding and fuel should be formed, it is of interest to be able to detect these flaws during interim inspections and inspect them thoroughly during postirradiation examinations (PIE). See Fig. 7.

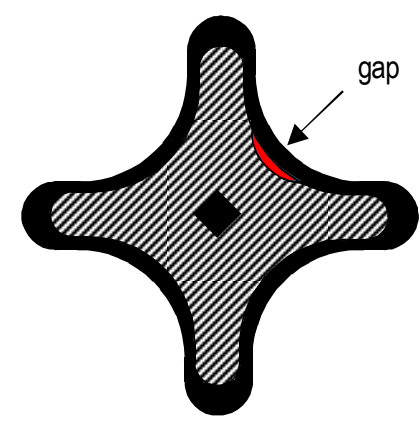
red.

Fig. 7. Cross-section of fuel rod with gap indicated. The gap is shown in

Since the metallic fuel is electrically conducting, it should be possible to detect the presence of a buried gap with eddycurrent measurements, although the fuel has quite low electrical conductivity relative to the cladding material, as can be seen in Table IV.

TABLE IV

ELECTRICAL CONDUCTIVITIES OF LIGHTBRIDGE FUEL AND CLADDING MATERIALS

\begin{tabular}{lll}
\hline \hline \multicolumn{1}{c}{ Part } & \multicolumn{1}{c}{ Material } & \multicolumn{1}{c}{$\begin{array}{c}\text { Electrical conductivity } \\
\left(\text { at } 20{ }^{\circ} \mathrm{C}\right)\end{array}$} \\
\hline Fuel & Uranium-Zirconium & $\sigma_{\text {fuel }}=\sim 0.63 \mathrm{MS} / \mathrm{m}$ \\
Cladding & Zirconium alloy & $\sigma_{\text {cladding }}=\sim 1.35 \mathrm{MS} / \mathrm{m}$ \\
\hline \hline
\end{tabular}

The materials are non-ferromagnetic.

Third-party eddy-current probes were tested on a representative sample, but the tested probes did not produce a reliable response to the gap buried beneath the cladding surface. A simple single-coil eddy-current probe for absolute 
mode operation [3] has therefore been designed for this purpose. The design process and test results are described in the subsequent sections. The current version of the probe is limited to performing gap-detection scans in the valleys of the fuel.

\section{A. Principle of eddy-current gap detection}

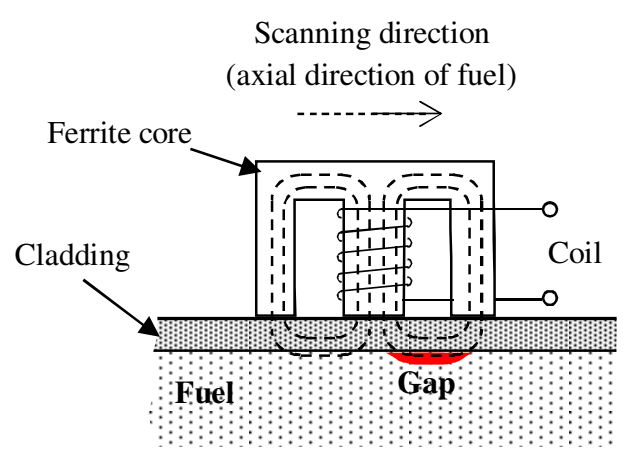

Fig. 8. Schematic illustration of a single-coil eddy-current probe scanning over a gap between fuel and cladding.

The eddy-current probe consists of a ferrite core wound with a copper winding. The winding is operated at high frequency $(250 \mathrm{kHz})$, and sets up a magnetic field as illustrated in Fig. 8. Since the ferrite core is open in the section facing the fuel rod surface, the magnetic field-lines fringe into the surface of the fuel rod.

The high-frequency magnetic field causes eddy currents to be induced in the parts of the fuel rod that coincide with the path of the magnetic field. Since the eddy-currents generate losses and attenuate the magnetic field, the probe impedance will be dependent on the geometry and composition of the fuel rod. Given that a significant part of the magnetic field penetrates beyond the fuel cladding and into the fuel, the occurrence of a gap can be detected as a change in the probe's impedance.

The terminals of the probe's coil are connected to an Elotest N300 electronics unit. For the simulations performed, a simplified representation of the impedance bridge circuit has been used. See Fig. 9.

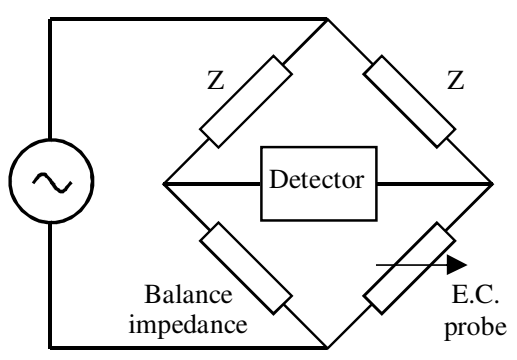

Fig. 9. Simplified impedance bridge circuit used for simulations. The balance impedance is a replicate of the eddy-current probe, but it is held at static conditions over a test sample.

The detector outputs a signal in the impedance plane with an in-phase (I) and quadrature (Q) component.
The bridge is balanced [3] at the beginning of a scan, so that all subsequent changes in the eddy-current probe's impedance during the scans shift the balance of the bridge away from zero output.

The phase of the impedance plane representation can be shifted, and gain can be applied individually to the I and Qaxes. As will be seen in subsequent paragraphs, the phase is shifted so that the gap-response is aligned with the Q-axis. This allows for a high gain to be separately applied to the gapresponse.

\section{B. Probe design}

The design process has been done iteratively, with finite element method (FEM) simulations in combination with mock-up tests at various frequencies.

Fig. 10 shows a screenshot from a 2D FEM study that was performed on a C-core geometry to investigate the magnetic field's ability to penetrate through the cladding layer. The slot opening $a$ was varied, and the impedance change in response to the gap was calculated. The simulations were performed at $250 \mathrm{kHz}$.

The results from these calculations indicate that a slot opening in the range $1-3 \mathrm{~mm}$ produces the highest response to a gap. This range has been used as a guideline in choosing probe-core geometries.

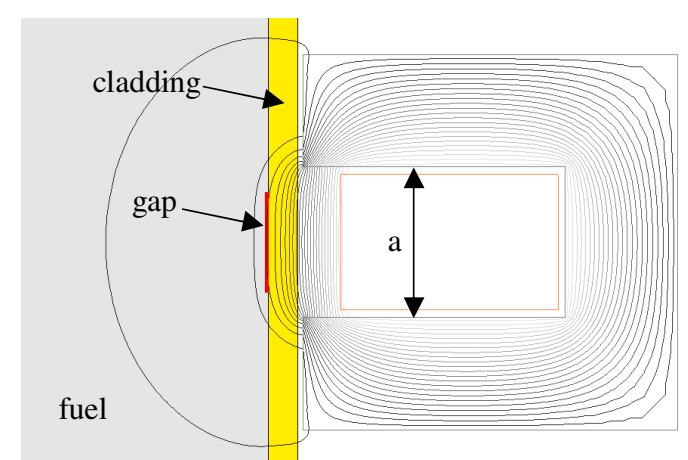

Fig. 10. Screenshot from a 2D FEM-study investigating the magnetic field penetration as a function of core slot-opening $a$. The simulations were performed at $250 \mathrm{kHz}$.

Several probe geometries have been simulated and tested as part of the design process. All designs have been based on commercially available ferrite cores. When iterating on the design, the various probes' sensitivity to the presence of gaps have been central in the evaluation of the performance of each probe design. The probe-cores also have to be sufficiently small to allow for smooth guidance along the surface of the helically twisted fuel rods. In practice, there was also a lower limit on core sizes due to the limitations set by the available equipment for winding and preparing the cores for mock-up tests.

Initially, $\mathrm{C}$ and E-cores in ferrite were assumed to be good candidates for use in the gap-detection probe. Although designs based on these core-types proved to be sensitive to the presence of gaps, they also have a large stray-field around the open part of the coil, which tended to give an unwanted response to surrounding structures. This interfered with the gap detection. 
After iterating on the design a core from TDK was chosen for the probe. It is an RM 4-core made out of N87 ferrite. Although it is not a fully closed cup-core [4], it was the best performing core among the tested geometries. The core has been modified so that it mates closely with the curved surface of the fuel cladding. Fig. 11 shows the core before and after modification.
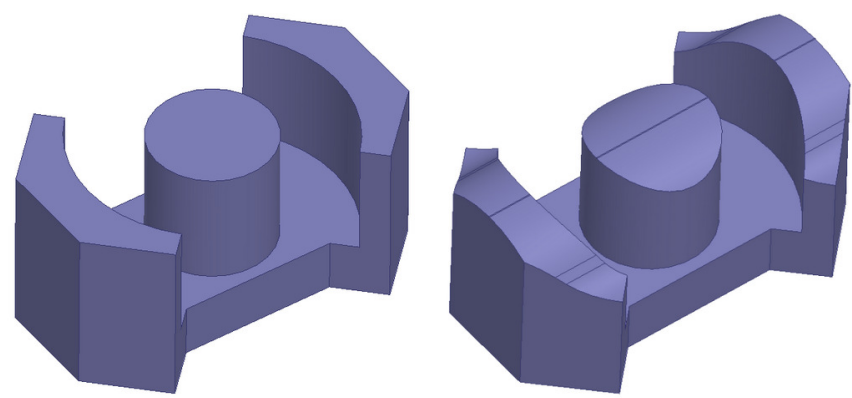

Fig. 11. Core before (left) and after (right) modification.

The main dimensions of the core are given in Fig. 12.

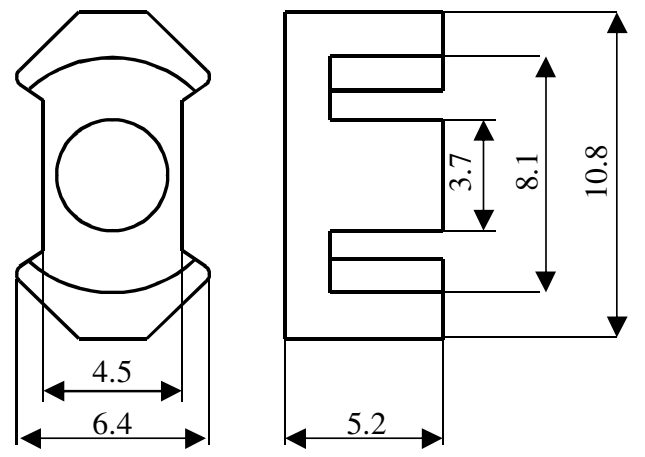

Fig. 12. Main dimensions of core. All dimensions are given in millimeters.

The core is wound with 40 turns of $0.15 \mathrm{~mm}$ copper wire. This wire dimension is sufficiently small for operation up to approximately $750 \mathrm{kHz}$.

Only the simulations and tests performed on the latest version of the probe are reported here.

\section{FEA of gap detection probe}

All FEM simulations have been performed in ANSYS Electromagnetics Suite. The probe has been modeled in 3D in eddy-current mode at $250 \mathrm{kHz}$. The model has been set up to calculate probe resistance and reactance.

Matlab has been used to simulate the measurement bridge's response to the changes in resistance and reactance in response to the presence of gaps. See Fig. 9.

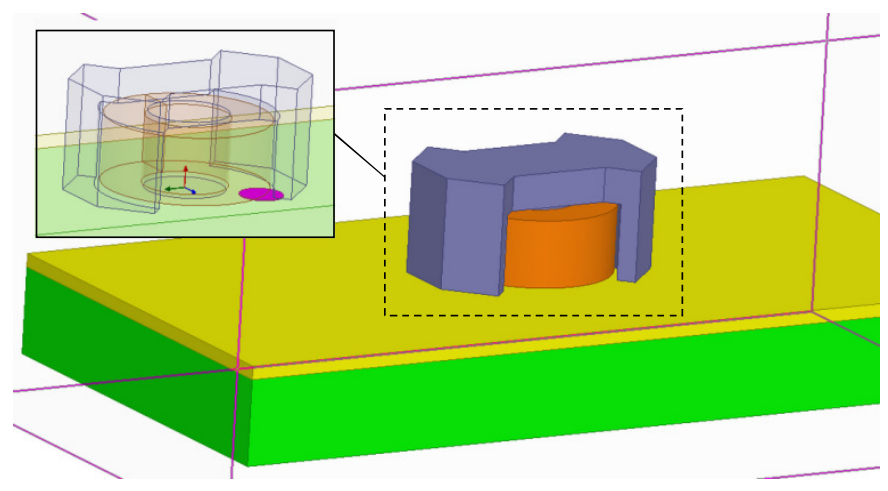

Fig. 13. FEM-model of probe. Picture inset at top left corner shows the gap in purple, located under the cladding layer.

The FEM simulation model is shown in Fig. 13. To reduce model complexity, the cladding and fuel have been modeled as flat. This simplification was necessary to preserve sufficient model resolution at acceptable computation times.

1) Gap simulations

In the inset in the top left corner of Fig. 13, the probe, cladding and fuel are rendered semi-transparent so that the gap geometry is visible in purple. The position of this gap geometry has been parameterized to enable multiple calculations to be performed with incremental changes in gap position.

Three different gap geometries have been simulated. These are shown in Fig. 14.

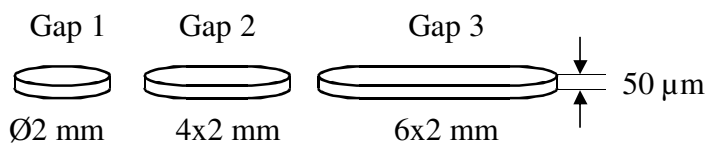

Fig. 14. Simulated gap geometries.

All three gaps are $50 \mu \mathrm{m}$ thick and $2 \mathrm{~mm}$ wide, whereas the length of the gaps varies from 2 to $6 \mathrm{~mm}$. The gaps are located under a cladding layer of thickness $0.61 \mathrm{~mm}$.

2) Lift-off simulations

In addition to simulating the response to gap-sweeps, liftoff simulations have been performed. These simulations show the response to the probe being removed from the surface of the fuel cladding as illustrated in Fig. 15.

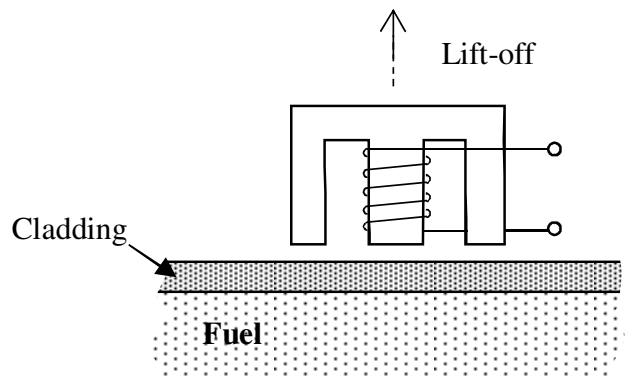

Fig. 15. Lift-off. The probe is removed from the surface of the fuel cladding 
The lift-off response was simulated to check the ability to distinguish between signal changes originating from the presence of a gap, and signal changes originating from improper surface contact, etc.

The lift-off simulations have been performed without the presence of any gaps. The lift-off was simulated from $0-1$ $\mathrm{mm}$.

\section{Simulation results}

The following three figures show the simulation results for each gap including lift-off. The results are presented in the impedance plane. The scale is identical in all three figures. The plane has been shifted so that the gap response is aligned with the Q-axis.

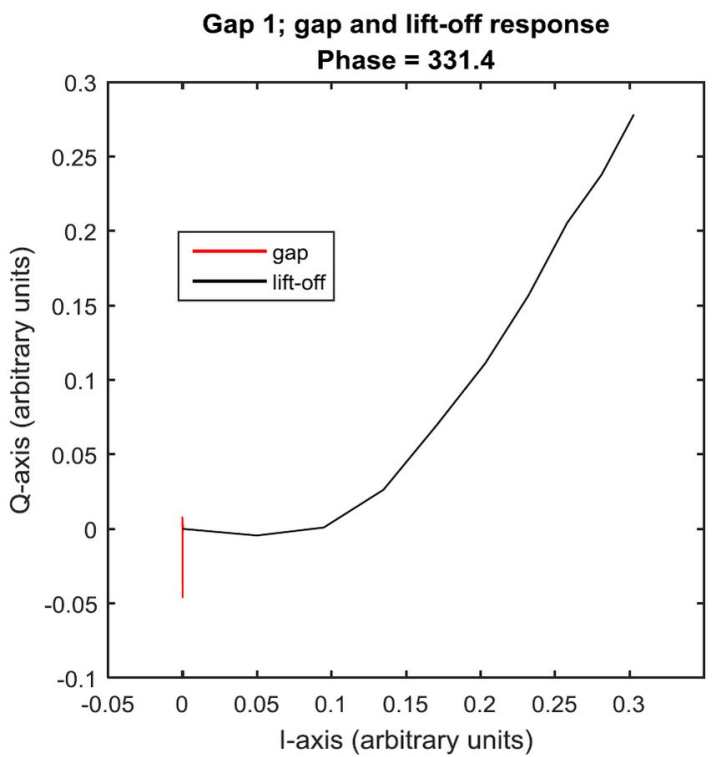

Fig. 16. Gap and lift-off response to simulated gap 1. The gap response is plotted in red, while the lift-off response is plotted in black.

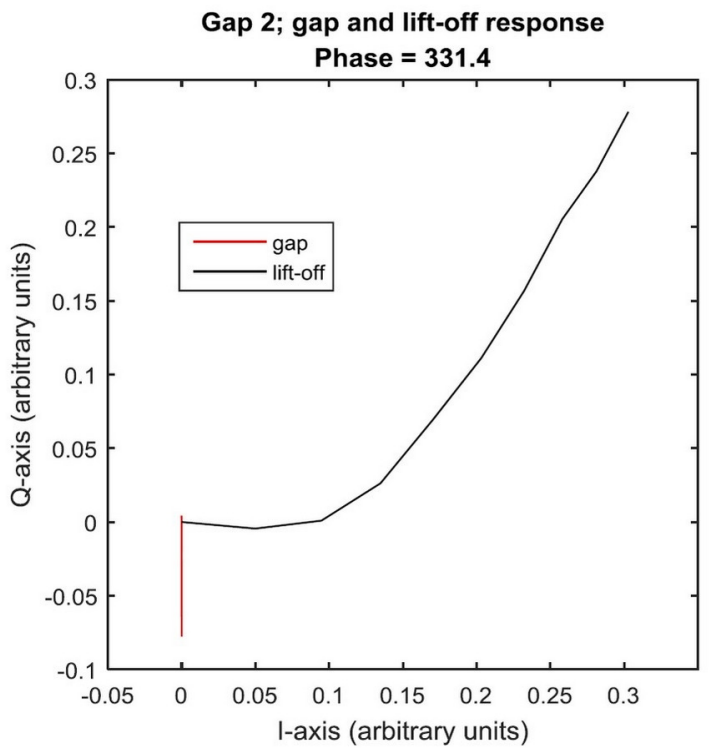

Fig. 17. Gap and lift-off response to simulated gap 2. The gap response is plotted in red, while the lift-off response is plotted in black.

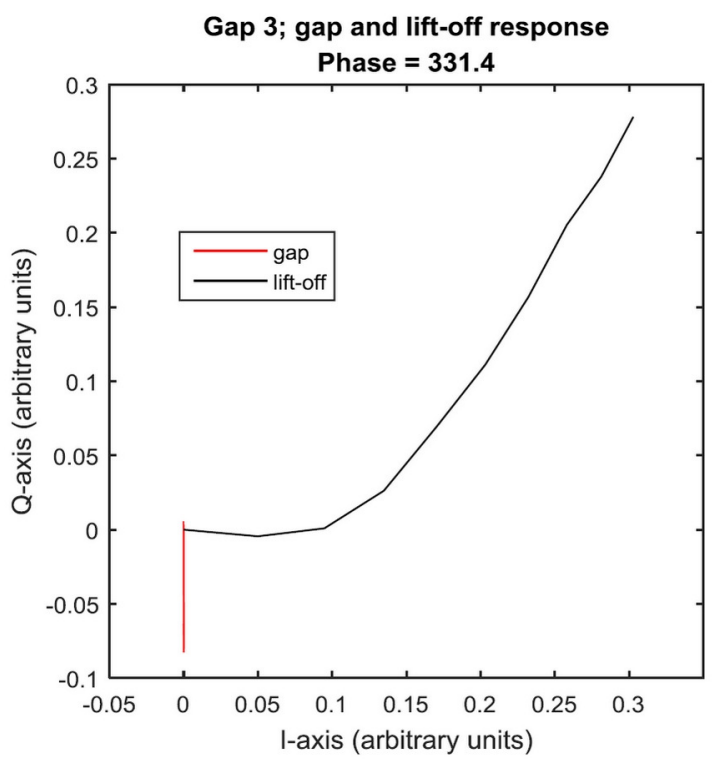

Fig. 18. Gap and lift-off response to simulated gap 3. The gap response is plotted in red, while the lift-off response is plotted in black.

The simulations results show good discrimination between gap and lift-off response. The gap-response amplitude also increases relative to the lift-off signal for increasing gap-sizes, as would be expected. Note that the underlying lift-off simulation is identical for all three figures.

In Fig. 19, the gap (Q-axis) responses have been plotted as a function of probe position. The three responses have been arranged in the same plot. All signals are in the same scale on both axes. The probe is symmetrical around the center leg, so the simulated half-wave response from each gap has been duplicated and mirrored around the center position to replicate a full sweep.

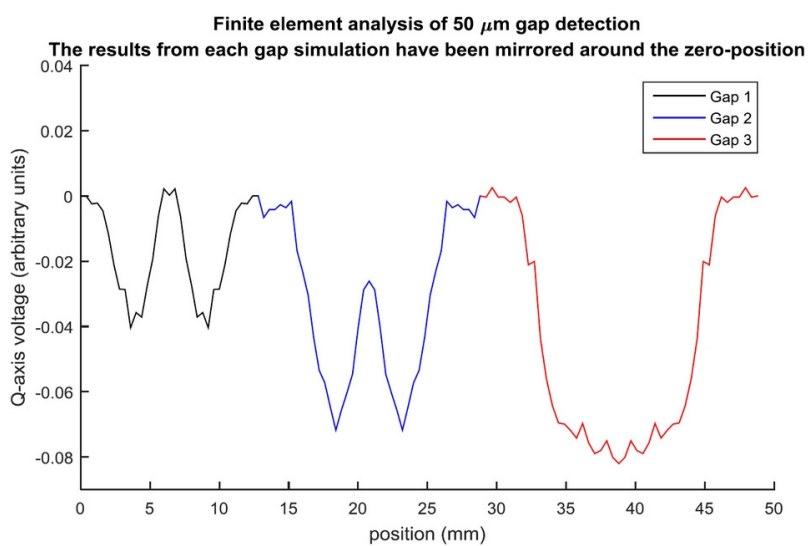

Fig. 19. Gap response vs. position. The results from the three simulations have been arranged in sequence. The three signal responses are in the same scale.

The simulated results show that the gap response amplitude increases with increasing gap lengths. The weakening in the gap response signal at the center position is also less pronounced for increasing gap lengths. A transition from a two-crested to a single-crested response can be observed when the gap-length reaches $6 \mathrm{~mm}$. 


\section{E. Mock-up tests}

A dummy fuel rod has been specifically designed and manufactured for testing of the eddy current probe. It consists of an inner part representing the fuel and an outer part representing the cladding. The parts have been produced by electrical discharge machining (EDM). On the surface of the part representing the fuel, several small gaps of different areas and depths have been milled. These gaps represent zones of de-bonding. The two dummy rod parts are shown prior to final assembly in Fig. 20. The inset picture shows the assembled dummy rod.

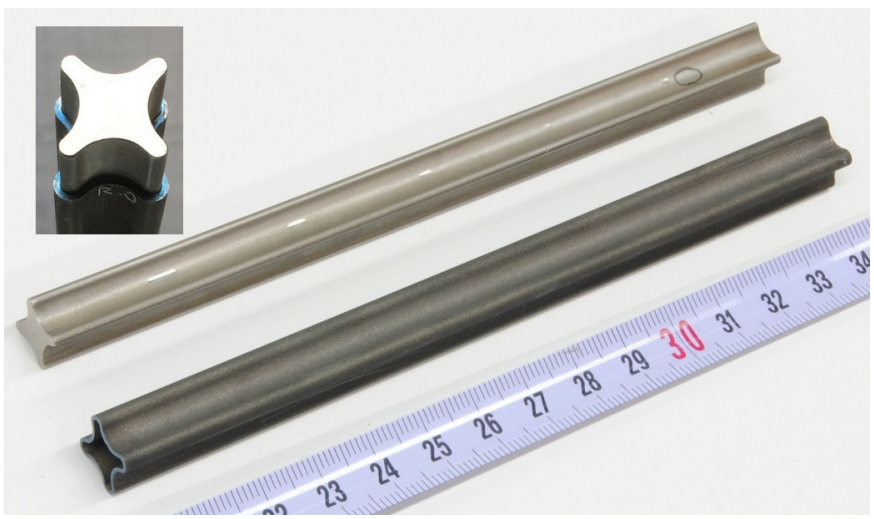

Fig. 20. Parts of dummy rod for eddy-current gap detection tests. The upper part represents the fuel, with small gaps machined onto the surface. The gaps shown are oval, whereas the opposite side is equipped with rectangular gaps. The lower part represents the cladding. The inset shows the assembled dummy rod. The dummy rod is not helically shaped.

An overview of the gap geometries on the two sides of the dummy rod is shown in Fig. 21.

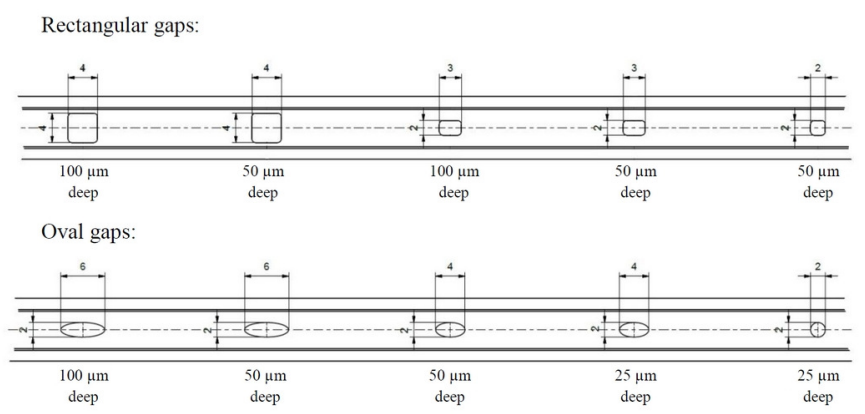

Fig. 21. Gap geometry with dimensions on the two opposite sides of the dummy rod. The same gap-geometry is reproduced in Figs. 25 and 26.

The materials for the parts have been chosen to represent the electrical conductivity of the actual fuel rod as close as possible. Table $\mathrm{V}$ summarizes the parameters of the selected materials.

TABLE V

ELECTRICAL CONDUCTIVITY OF DUMMY ROD MATERIALS

\begin{tabular}{lll}
\hline \hline \multicolumn{1}{c}{ Part } & \multicolumn{1}{c}{ Material } & \multicolumn{1}{c}{$\begin{array}{c}\text { Electrical conductivity } \\
\left(\text { at } 20{ }^{\circ} \mathrm{C}\right)\end{array}$} \\
\hline Fuel & Titanium Grade 5 & $\sigma_{\mathrm{Ti}-5}=0.562 \mathrm{MS} / \mathrm{m}$ \\
Cladding & $\mathrm{Zy}-4$ & $\sigma_{\mathrm{Zy}-4}=1.35 \mathrm{MS} / \mathrm{m}$ \\
\hline \hline
\end{tabular}

The gap-detection probe is shown integrated with the measurement probe holder in Fig. 22. The wound core is integrated with a spring-loaded guiding system to enable steady positioning to the cladding surface while the rod moves in the axial direction.

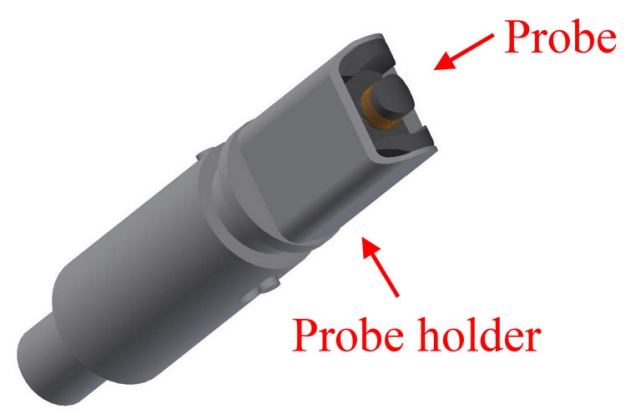

Fig. 22. Rendering of gap-detection probe mounted in probe-holder.

In Fig. 23, the probe and probe-holder is shown mounted in the mock-up measurement station.

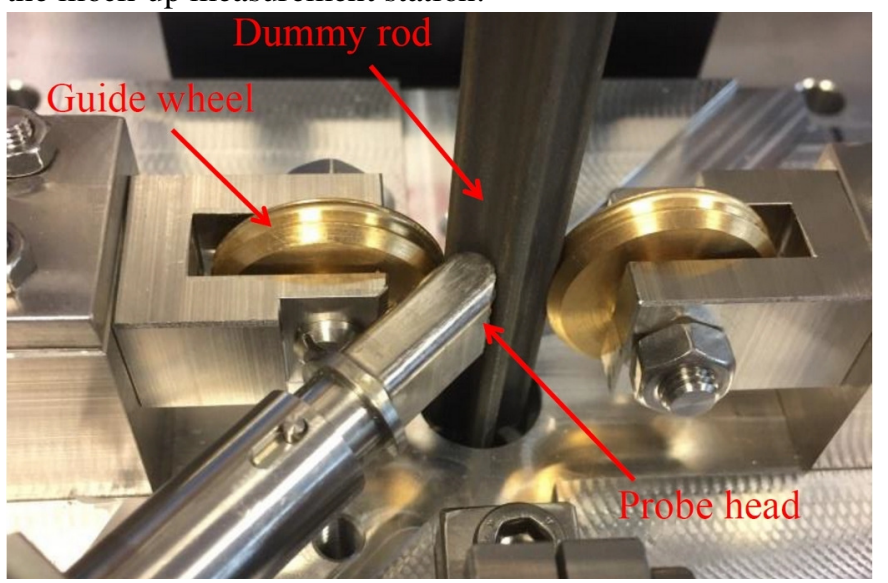

Fig. 23. Close-up of dummy fuel rod and gap-detection probe in measurement station mock-up.

\section{F. $\quad$ Test results}

Fig. 24 shows the response to the $50 \mu \mathrm{m}$ deep $4 \times 4 \mathrm{~mm}$ rectangular gap combined with a lift-off signal. The good separation between gap and lift-off responses allow for heavy gain to be applied to the gap (Q-axis) signal. 


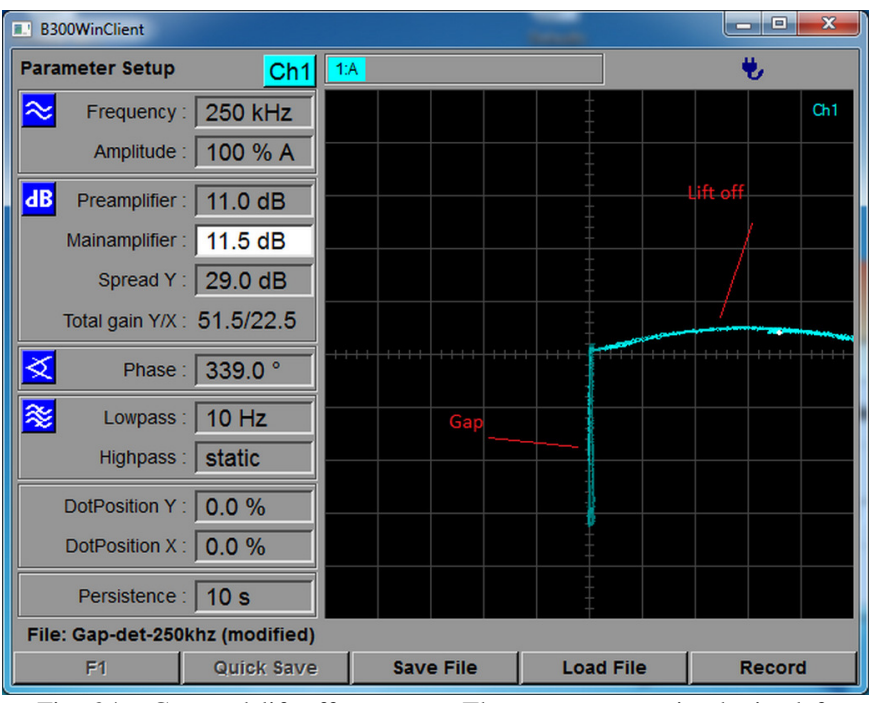

Fig. 24. Gap and lift-off response. The gap-response is obtained from scanning a $50 \mu \mathrm{m}$ deep $4 \times 4 \mathrm{~mm}$ rectangular gap.

The gap/lift-off discrimination was similarly good for the other gaps.

The separation in the gap and lift-off response (including phase) is similar to the simulated results in Figs. 16-18.

The two next figures show the gap (Q-axis) response as a function of dummy rod position. Since it proved difficult to obtain sufficiently good contact between the fuel and cladding parts of the dummy rod, it was necessary to shorten the length of the cladding part with a few centimeters. This significantly improved the contact between the parts, but the outermost gaps on each side were affected by this modification, as can be seen in the plots.

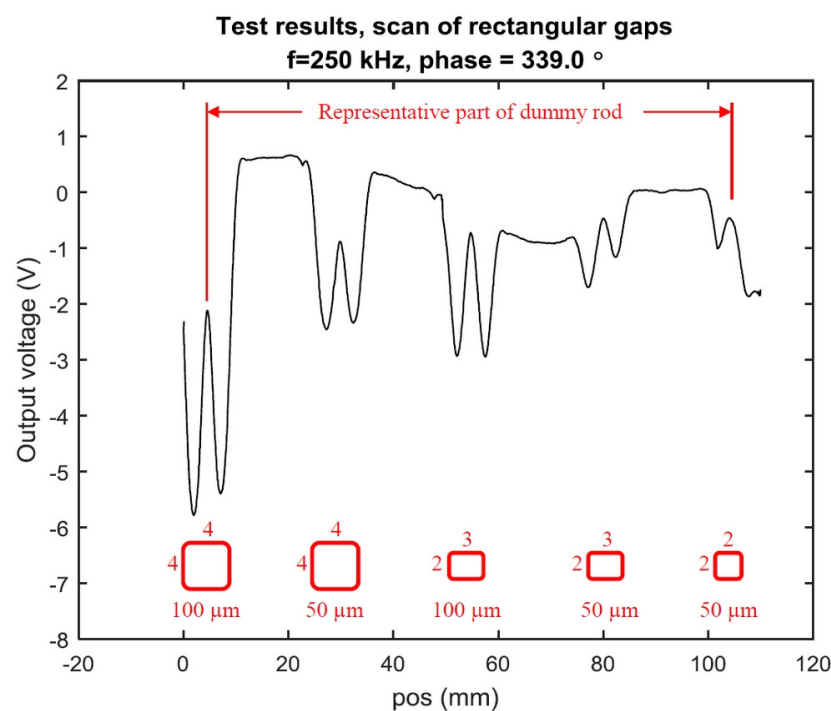

Fig. 25. Test results from gap-detection scan on the side of the dummy rod with rectangular gaps. The dimensions (in millimeters) and depth of each gap is included in the figure.

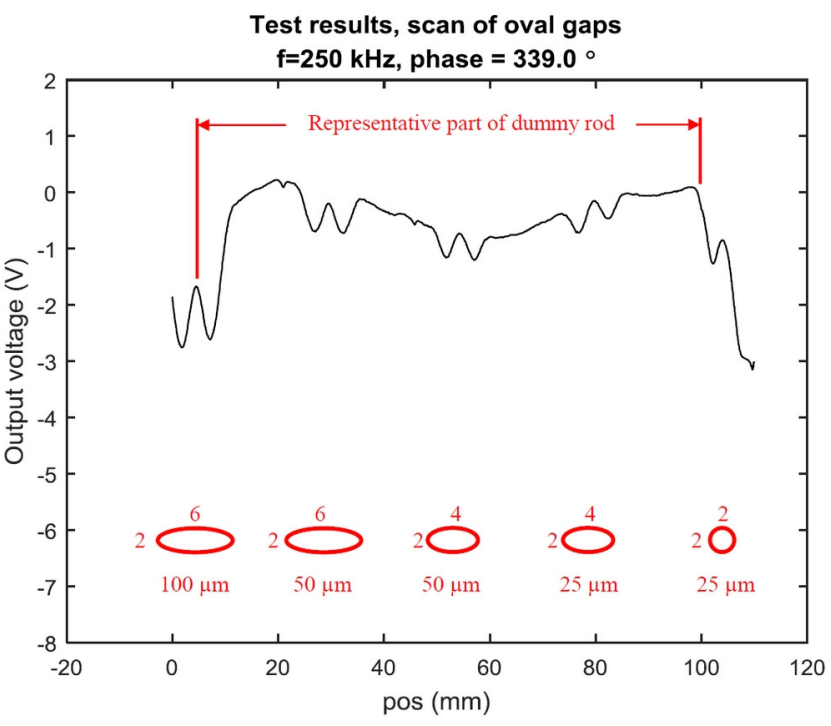

Fig. 26. Test results from gap-detection scan on the side of the dummy rod with oval gaps. The dimensions (in millimeters) and depth of each gap is included in the figure.

The test results show that the crack detection probe is able to produce a distinctive response to each of the gaps. The signal drift between the gaps is believed to be a response to a small opening between the fuel and cladding part of the dummy rod, since it was very difficult to obtain a perfect fit between the two.

The gap-detection probe is generally more sensitive to the rectangular gaps, but also gives a distinct response to oval gaps with thickness as low as $25 \mu \mathrm{m}$. Also note that all scans were performed at the same phase.

There is correspondence between simulated and experimental results, but the transition from a double-crested to a single-crested response is not observed in the practical tests, as predicted in the simulated gap-response rightmost in Fig. 19. It is still expected that such a response will be observed for longer gap lengths.

\section{ACKNOWLEDGMENT}

The authors wish to thank the personnel at the instrument workshop in the NEW-department at IFE for their know-how and dedicated effort in manufacturing and assembling the test equipment.

\section{REFERENCES}

[1] J. Malone, A. Totemeier, N. Shapiro, S. Vaidyanathan, "Lightbridge Corporation's advanced metallic fuel for light water reactors," Nuclear Technology., vol. 180, pp. 437-442, Dec. 2012.

[2] M.A. McGrath, P. Bennett, H. Thoresen, "Utilization of the Halden Reactor for supporting development of fuel with enhanced accident tolerance," presented at Top Fuel Boise, ID, USA, Sept. 11-15, 2016.

[3] T. Stepinski, "Essential parameters in eddy current inspection," Uppsala University, Uppsala, Sweden, SKI report 00:30, May 2000.

[4] J. Blitz, Electrical and magnetic methods of non-destructive testing, 2nd ed., London, UK: Chapman \& Hall, 1997, pp. 139-141. 